\title{
Analyzing the Essential Proteins Set of Plasmodium Falciparum PF3D7 for Novel Drug Targets Identification Against Malaria
}

\section{Fawad Ali}

Abdul Wali Khan University Mardan

Hira Wali

Abdul Wali Khan University Mardan

Saadia Jan

Abdul Wali Khan University Mardan

\section{Muneeba Aslam}

Abdul Wali Khan University Mardan

\section{Imtiaz Ahmad}

Abdul Wali Khan University Mardan

\section{Sahib Gul Afridi}

Abdul Wali Khan University Mardan

\section{Suliaman Shams}

Abdul Wali Khan University Mardan

Asifullah Khan ( $\square$ asifullah111@gmail.com)

Abdul Wali Khan University Mardan https://orcid.org/0000-0002-1444-4249

\section{Research}

Keywords: Plasmodium falciparum, malaria, comparative proteomics, anti-malarial therapeutics

Posted Date: April 5th, 2021

DOI: https://doi.org/10.21203/rs.3.rs-383876/v1

License: (c) (i) This work is licensed under a Creative Commons Attribution 4.0 International License. Read Full License

Version of Record: A version of this preprint was published at Malaria Journal on August 3rd, 2021. See the published version at https://doi.org/10.1186/s12936-021-03865-1. 


\section{Abstract}

Background: Plasmodium falciparum is an obligate intracellular parasite of humans that causes malaria. P. falciparum is a major public health threat to human life responsible for high mortality. Currently, the risk of multi-drug resistance of $P$. falciparum is rapidly increasing. There is a need to address new anti-malarial therapeutics strategies to combat the drug-resistance threat.

Methods: We retrieved the $P$. falciparum essential proteins from the recently published studies. Pathogen essential proteins were initially scanned against human host and its gut microbiome proteome sets by comparative proteomics analyses. The human host nonhomologs essential proteins of $P$. falciparum were additionally analyzed for druggability potential via in silico methods to possibly identify novel therapeutic targets.

Results: The analyses identified six P. falciparum essential and human host non-homolog proteins that follow the key druggability features. These druggable targets have not catalogued so far in the Drugbank repository. These prioritized proteins seem novel and promising drug targets against $P$. falciparum due to their key protein-protein interactions features in pathogen-specific biological pathways and to hold appropriate drug-like molecule binding pockets.

Conclusion: The prioritized protein targets may worthy to test in malarial drug discovery program to overcome the anti-malarial resistance issues. The in-vitro and in-vivo studies might be promising for additional validation of these prioritized lists of drug targets against malaria.

\section{Background}

Malaria is a life-threatening infectious disease caused by parasitic protozoan plasmodium. It is a vector born disease, transmitted to humans through the bite of infected carrier female anopheles mosquitoes. Among five parasite species that cause malaria in humans, the two species, i.e. P. falciparum and $P$. vivax have the greatest threat to human life [1]. The $P$. falciparum, a unicellular protozoan, belongs to the family Plasmodiidae and lies in the phylum Apicomplexa [2]. $P$. falciparum is the most deadly parasite and the major cause of morbidities and mortalities. About $50 \%$ of all the malarial cases caused due to $P$. falciparum $[3,4]$. The $P$. falciparum alone responsible for almost all malaria-inflicted deaths in Sub-Saharan Africa, with the continent bearing over $90 \%$ of the global $P$. falciparum burden [5]. Asia is second to Africa in terms of malaria prevalence. In 2019, the WHO estimated 229 million malaria cases and about 409,000 deaths due to malaria worldwide [6]. More than $85 \%$ of confirmed recorded cases and deaths in Asia occurred in India, Indonesia, Myanmar, and Pakistan [7].

Many approved drugs, including chloroquine and the most recent anti-malarial drug Artemisinin, were found to be ineffective against $P$. falciparum [8]. Resistance to chloroquine was first observed in Thailand in 1957 and the Colombian-Venezuelan border in 1959 [9]. Drug resistance had spread across Sub-Saharan Africa by 1988 and today chloroquine is no longer effective in almost all parts of the world [10]. Specific polymorphisms in the $P$. falciparum chloroquine resistance transporter (PfCRT) have been found to be strongly linked to chloroquine resistance [11]. Likewise, the artemisinin resistance is observed in many regions of the world and was first documented in 2008 in the Thailand-Cambodia border regions $[12,13]$. The artemisinin resistance was first associated with delayed parasitic clearance after three days of artemisinin monotherapy. Many studies have reported that artemisinin resistance emerged due to polymorphism in the $p f k 13$ gene $[14,15]$.

The indispensable proteins of $P$. falciparum recently explored from well experimental approaches in some studies. These repositories are promising to identify suitable targets to overcome the drug-resistant $P$. falciparum infection $[16,17]$. The Zhang et al., (2018) experimentally analyzed 5399 genes and identified 2680 as essential for optimal growth of $P$. falciparum during asexual blood stages. These essential genes coding the $P$. falciparum vital proteins, including drug targets and potential vaccine candidates. Besides, there are over 1,000 of plasmodium-conserved essential genes with unknown biological functions so far. In the current study, these essential proteins were retrieved from the two recently published studies and assessed for druggable potential based on comparative proteomics, protein-protein interactions and drug-like molecules binding potential.

\section{Methodology}

The methodological layout of the current study is depicted in Fig. 1.

\section{Retrieval of non-paralogous essential proteins}


The essential proteins of $P$. falciparum strain 3D7 were retrieved from two recently published studies [i.e. 16, 17]. The paralogous proteins were removed by CD-HIT clustering analysis with $80 \%$ sequence similarity cutoff [18].

\section{Human host non-homologous and virulent proteins identification}

The $P$. falciparum essential proteins non-homolog to human host were identified by comparative sequence analyses via BLASTp tool [19]. The threshold values of $35 \%$ query coverage and sequence identity were set during this analysis [20]. The proteins having significant similarity with human proteome were discarded and the remaining non-homologs were shortlisted for further analysis. The non-homology search against human gut microbiota proteins sequences was also carried out with a threshold cutoff, i.e. E value 0.001 $[21,22]$. The Vectors database was screened for $P$. falciparum 3D7 virulent proteins annotation. The Vectors database contains 5304 virulent proteins data from various parasites including $P$. falciparum [23].

\section{Drugbank database scanning}

The shortlisted essential proteins of $P$. falciparum from above analyses were scanned against the Drugbank database to identify novel drug targets with $60 \%$ query coverage and percent identity threshold of BLASTp [24].

\section{Structure homologs search}

The proteins data bank (PDB) was screened to identify the homologous 3D structures of pathogenic proteins [25]. The pathogen proteins were BLAST against the entire PDB database entries with $60 \%$ percent sequence identity and query coverage $[26,22]$. The pathogen sequences having < 60\% homology were modeled with Swiss Model [27] and verified by ERRAT [28] and RAMPAGE [29].

\section{Druggablity analysis}

The prioritized list of essential proteins shortlisted from above analyses were tested for druggability potential. The drug-like molecules binding pockets of the targets were identified by PockDrug-server [30]. The subcellular localization was performed with CELLO v.2.5 [31]. The protein-protein interaction (PPI) and molecular weight analysis were performed [32]. The PPI analysis was performed by STRING database and the Hub proteins were identified based on node degree $(K \geq 5)$ that represent the number of interactions [33].

\section{Results}

\section{Subtractive proteomic analyses}

Essential genes perform key cellular functions for the survival of pathogens [34]. The $P$. falciparum strain 3D7 essential genes information were obtained from the recently published articles $[16,17]$ and total 3380 essential protein were identified. These proteins sequences were retrieved from Uniprot. Seven paralogous protein sequences were excluded by CD-HIT analysis and the remaining 3373 sequences were considered for downstream analysis (Supplementary Table S1). The non-paralogous protein sequences were subjected to BLASTp against human proteome as well as human gut microbiome proteome data with threshold parameters. The gut flora is helpful to the host in many ways like vitamins biosynthesis and absorption of short chain-fatty acids [35]. The unintended inhibition of gut microbe leads to a decrease in gut flora and colonization of pathogenic bacteria in the host gut [36]. The comparative sequences analyses identified total 183 P. falciparum strain 3D7 essential proteins non-homologous to human as well as human's gut flora proteins (Supplementary Table S2). The homology screening against Drugbank repository for these 183 proteins inferred no homology with already reported drug targets deposited in drugbank database. The five among these 183 were annotated as $P$. falciparum 3D7 virulent proteins during screening of Vectors database (Table 1).

Table 1

The P. falciparum 3D7 essential virulent proteins, non-homolog to human host as well as human gut microbiome proteome.

\begin{tabular}{|llll|}
\hline & Protein Accession number & Protein Name & Nature of protein \\
\hline 1 & Q9TY99_PLAF7 & knob-associated histidine-rich protein & Virulent \\
\hline 2 & Q8I5P1_PLAF7 & Cell traversal protein for ookinetes and sporozoites (CelTOS), putative & Virulent \\
\hline 3 & C6KTB1_PLAF7 & 4-methyl-5(B-hydroxyethyl)-thiazol monophosphate biosynthesis enzyme & Virulent \\
\hline 4 & Q8I6Z5_PLAF7 & plasmepsin V & Virulent \\
\hline 5 & Q8IDM6_PLAF7 & nucleoside transporter 1 & Virulent \\
\hline
\end{tabular}




\section{Druggability analyses}

The Drugbank non-homologous proteins were prioritized for downstream druggability analyses. The subcellular localization is one of the key aspect of druggability and the cytoplasmic proteins are considered as suitable drug targets [37, 38]. The 15 P. falciparum proteins among shortlisted prioritized targets were annotated as cytoplasmic proteins. The proteins 3D structures identified by Swiss model were validated with the ERRAT tool with quality factor score of $>50$, which is accepted as high quality model [39]. Ramachandran plot identified $80-90 \%$ of modeled proteins residues in the allowed region assuring good quality structure modeling of the target proteins (Table 2). Finally, six (06) proteins were prioritized on the basis of (i) pockdrug probability score $₫ 0.5$ [30], (ii) ERRAT quality factor $\geq 90$ [28], and (iii) protein-protein interaction node degree i.e. $K \geq 5$ [33] (Table 2) (Fig. 2). These six prioritized targets are speculating to hold promising druggable pockets to anchor small drug-like molecules and act as indispensable hub proteins in P. falciparum metabolic network. 
Table 2

Druggability analysis of shortlisted 15 cytoplasmic proteins of $P$. falciparum 3D7 essential and human host non-homolog proteins. The steric $^{\star}$ indicates shortlisted 06 best druggable targets.

\begin{tabular}{|c|c|c|c|c|c|c|c|c|}
\hline $\begin{array}{l}\text { Uniprot } \\
\text { accession } \\
\text { numbers }\end{array}$ & $\begin{array}{l}\text { PDB } \\
\text { homolog } \\
\text { ID's }\end{array}$ & Protein Names & $\begin{array}{l}\text { ERRAT } \\
\text { Quality } \\
\text { Factor }\end{array}$ & $\begin{array}{l}\text { Ramachandran } \\
\text { plot (residues } \\
\text { in favored } \\
\text { region \%) }\end{array}$ & $\underset{>-4}{\text { QMEAN }}$ & $\begin{array}{l}\text { Pock } \\
\text { Drug } \\
\text { score > } \\
0.5 \\
\text { (Residues } \\
\text { in } \\
\text { pocket) }\end{array}$ & $\begin{array}{l}\text { Molecular } \\
\text { weight } \\
\text { (Dalton) }\end{array}$ & $\begin{array}{l}\text { Node } \\
\text { degree } \\
\text { (K) } \geq 5 \\
\text { (STRING } \\
\text { analysis) }\end{array}$ \\
\hline 097259_PLAF7 & 3fga.1.C & $\begin{array}{l}\text { Serine/threonine- } \\
\text { protein } \\
\text { phosphatase }\end{array}$ & 99.3103 & $94.75 \%$ & -2.11 & $0.24(15)$ & 35765.00 & 7.45 \\
\hline COH4F3_PLAF7* & 5cfi.1.A & $\begin{array}{l}\text { Bis(5'-nucleosyl)- } \\
\text { tetraphosphatase } \\
\text { [asymmetrical] }\end{array}$ & 96.1832 & $97.20 \%$ & -0.37 & $0.98(8)$ & 17750.19 & 6.36 \\
\hline Q8I3A9_PLAF7 & 4nc6.1.A & $\begin{array}{l}\text { GTPase- } \\
\text { activating protein, } \\
\text { putative }\end{array}$ & 90.2778 & $90.71 \%$ & -3.37 & $0.99(20)$ & 50301.05 & 4.36 \\
\hline Q8I2N2_PLAF7* & 4lac.1.C & $\begin{array}{l}\text { Serine/threonine- } \\
\text { protein } \\
\text { phosphatase }\end{array}$ & 93.5484 & $97.54 \%$ & -0.72 & $0.91(14)$ & 36386.98 & 6.18 \\
\hline Q8I082_PLAF7 & 1ryt.1.A & Rifin & 69.7368 & $93.41 \%$ & -2.95 & $0.32(10)$ & 40648.33 & 3.82 \\
\hline Q8IIU3_PLAF7 & 2c9o.1.A & RuvB-like helicase & 88.7505 & $92.14 \%$ & -2.41 & & 53405.94 & 7.45 \\
\hline Q8I599_PLAF7* & 2ibj.1.A & $\begin{array}{l}\text { Cytochrome b5, } \\
\text { putative }\end{array}$ & 94.5205 & $95.00 \%$ & -0.14 & $1(19)$ & 18244.08 & 6.55 \\
\hline Q8IDG3_PLAF7 & 6muw.1.C & $\begin{array}{l}\text { Proteasome } \\
\text { subunit alpha } \\
\text { type }\end{array}$ & 92.2727 & $93.72 \%$ & -1.63 & & 27947.73 & 10 \\
\hline Q8IM27_PLAF7* & 2a22.2.A & $\begin{array}{l}\text { Vacuolar protein } \\
\text { sorting- } \\
\text { associated } \\
\text { protein } 29\end{array}$ & 92.3977 & $95.63 \%$ & 0.23 & $0.96(16)$ & 21774.02 & 5.09 \\
\hline Q8IM19_PLAF7* & 6k0x.1.B & $\begin{array}{l}\text { Multifunctional } \\
\text { methyltransferase } \\
\text { subunit TRM112, } \\
\text { putative }\end{array}$ & 92.233 & $91.80 \%$ & -1.87 & $1(10)$ & 14234.31 & 8.18 \\
\hline Q8ILZ5_PLAF7 & 6y4l.1.A & $\begin{array}{l}\text { ER membrane } \\
\text { protein complex } \\
\text { subunit } 2\end{array}$ & 100 & $95.92 \%$ & -2.03 & $0.97(16)$ & 34952.82 & 4.36 \\
\hline C6S3I2_PLAF7 & 6t69.1.A & $\begin{array}{l}\text { MORN repeat- } \\
\text { containing protein } \\
5\end{array}$ & 68.3333 & $87.14 \%$ & -0.84 & $0.98(12)$ & 17938.95 & 1.33 \\
\hline Q8IKK5_PLAF7 & 1w98.1.B & $\begin{array}{l}\text { Mediator of RNA } \\
\text { polymerase II } \\
\text { transcription } \\
\text { subunit 20, } \\
\text { putative }\end{array}$ & 88.6179 & $93.80 \%$ & -3.17 & $0.99(11)$ & 36709.76 & \\
\hline Q8IKC5_PLAF7 & 4I02.1.A & $\begin{array}{l}\text { Diacylglycerol } \\
\text { kinase }\end{array}$ & 85.8025 & $81.58 \%$ & -8.09 & $0.98(32)$ & 57642.42 & 7.09 \\
\hline Q8ID85_PLAF7* & 4ww4.1.B & RuvB-like helicase & 91.3242 & $94.46 \%$ & -1.49 & $1(14)$ & 54629.36 & 7.27 \\
\hline
\end{tabular}

\section{Discussion}

In the current study, the 3380 essentially reported proteins of $P$. falciparum strain 3D7 were analyzed to address potent novel druggable targets. These proteins were analyzed based on their non-homology with the human host as well as human gut microbiome proteome. The targets were additionally shortlisted based on strict threshold criteria of basic druggability features. Among the shortlisted targets 
(Table 2), the protein, Bis(5'-nucleosyl)-tetraphosphatase (asymmetrical) (COH4F3_PLAF7) also known as asymmetrical diadenosine 5',5"-P1,P4-tetraphosphate hydrolase (PfAp4A) (EC 3.6.1.17) is an enzyme belongs to the hydrolase family [40]. This enzyme participates in pyrimidine and purine metabolism [41]. The PfAp4A hydrolase exhibited high-temperature stability even at $60^{\circ} \mathrm{C}$ [42]. Previously in few studies, the PfAp4A is also tested as a potential drug target against $P$. falciparum $[43,44]$.

The protein serine/threonine-protein phosphatase (Q8I2N2_PLAF7) was also found among finally shortlisted target that involve in regulation of many cellular signaling pathways by catalyzing the removal of phosphate group from target enzymes. This enzyme plays a central role in the functional regulation and control of different genes related to the cell cycle [45]. The phosphorylation regulates several primary steps in P. falciparum's diverse life cycles. Many of the kinases and phosphatases as well as their substrates are specific to parasites, making eventually the phosphorylation event as a viable target for anti-parasitic action [46]. The protein phosphatase-1, a type of PfPPP, involve in the mitotic division of $P$. falciparum and plays an important role in the liberation of merozoites. Prior studies on $P$. falciparum revealed that the activity of PfPP1 is more important as compared to protein phosphatase 2A (PP2A) [47]. This also verified by transcriptomic analysis, where the PfPP1 transcript levels reported higher than PP2A after 24 hours of RBC infection [48]. The okadaic acid (OA), a toxin initially isolated from a marine sponge, i.e. Halichondria okadai has been identified as a selective inhibitor of serine/threonine protein phosphatases (PPPs) and reported to strongly inhibits PP1, 2A, and 2B in-vitro [49]. Out of 30 examined protein phosphatase, the 16 protein phosphatases along with PP1 and putative phosphatases seem to be important for blood-stage parasites [47]. Moreover, some studies also showed that PfPP1 is indispensable for blood-stage parasite survival [50]. Many phosphatases play key roles in the pathological pathways, and their inactivation may help to prevent or postpone the emergence of human diseases. Therefore, the potent inhibitors for such phosphatases might be of great therapeutic benefit.

The enzyme cytochrome b5 Reductase (cb5r) (Q81599_PLAF7) plays a role in fatty acid elongation, cholesterol biosynthesis, and cytochrome P450-mediated detoxification of xenobiotics [51]. This protein has been thoroughly studied in mammals, but still need to be characterized in microorganisms, such as fungi and parasites, including $P$. falciparum. There is a close phylogenetic relationship between the plant and $P$. falciparum cb5r proteins. The plant cb5r has been identified as a novel herbicidal target [51]. This protein reported essential for $P$. falciparum survival and was found human host non-homolog and possibly a potent therapeutic target, thereby might be a worthy candidate for drug development against malaria.

The vacuolar protein sorting-associated protein 29 (VPS29) (Q8IM27_PLAF7) is involved in the essential metabolic process of proteins translocation to the subcellular organelles. The $P$. falciparum sort and traffic newly synthesized proteins to target intracellular organelles as well as beyond the plasma membrane into the host cell in some cases [52]. The $P$. falciparum VPS29 (i.e. PfVPS29) is the functional component in the assembly of the retromer complex [53]. During the PPI analysis, the pfVPS29 shows direct interactions with other retromer complex components i.e. PfVPS26, VPS9, VPS10 as shown in Fig. 2. The PfVPS29 is located in the cytosol and highly expressed in early trophozoite and schizont stages [54]. Inhibiting the activity of PfVPS29 may lead to the disassembling of the retromer complex and possibly halt the protein sorting function of the $P$. falciparum.

The multifunctional methyltransferase subunit (Q8IM19_PLAF7) have methyltransferase activity during post-translational modifications, chromatin remodeling and protein heterodimerization activity [40]. The protein methyltransferases (PMTs) have been linked to the pathogenesis of a variety of diseases, including human cancers, inflammatory diseases, metabolic diseases, and neurodegenerative diseases. The PMTs are highly attractive among the histone-modifying enzymes and act as drug targets $[55,56]$. However, to date no study been conducted about the targeting or inhibition of $P$. falciparum methyltransferase.

The RuvB-like helicase (Q8ID85_PLAF7) also shortlisted as therapeutic target in the current study. The RuvB-like helicase function like ATP- dependent helicases. It has a vital role in the cell cycle and transcription $[57,58,59]$. The RUVBL proteins (RUVBL1 \& 2) are known to regulate various essential cellular processes in different organisms like $S$. cerevisiae, drosophila and $C$. elegans [60, 61, 62]. Three types of RuvB, i.e., PfRuvB1, PfRuvB2, and PfRuvB3 are present in the $P$. falciparum. The PfRuvB1 possesses ssDNA-stimulated ATPase activity and function as a helicase that unwind the DNA in a $5^{\prime}$ to $3^{\prime}$ direction [58]. The PfRuvB2 works similar to PfRuvB1, however, its helicase activity is comparatively weak. The PfRuvB3 function only as ATPase with no helicase activity during schizont/merozoits or interaerythocytic mitosis [63]. During the developmental stages of the parasite, the PfRuvB1 and PfRuvB2 are expressed in the asexual phase, while the PfRuvB3 expresses only during the schizont stage, where intraerythrocytic mitosis of $P$. falciparum occurs [64]. The PfRvuBL3 protein is a true homolog of yeast RuvBL2. Since in yeast, RuvBL proteins are shown to be extremely essential for survival and known to regulate the transcription of almost $5 \%$ of yeast genes [60]. The RuvB- like helicases are suitable drug targets to control malaria due to their essentiality for pathogen and non-homology with human host proteome. It is reported that helicases are needed for the proliferation of bacteria, viruses and plasmodium, and inhibiting the DNA unwinding activity reduces the replication of these 
pathogens in cell cultures and animal models $[65,66,67]$. The PfRuvB1 ATPase activity is formerly reported to be inhibited by actinomycin, novobiocin, and ethidium bromide [68].

\section{Conclusion}

We took advantage from the recently published essential proteins of $P$. falciparum and employed the comparative subtractive proteomics in couple with in silico druggability approaches to identify novel and suitable drug targets against $P$. falciparum. The study based on comparative sequence analysis, updated biological databases scanning and multi-direction druggability analyses. This ultimately prioritized and addressed several novel druggable targets against $P$. falciparum infection not highlighted before. Additional consideration of these shortlisted targets in future drug discovery projects may worthy to combat the anti-malarial drug-resistant issues.

\section{Abbreviations}

Pf: Plasmodium falciparum

WHO: World Health Organization

PfCRT: Plasmodium falciparum Chloroquine resistant transporter

Pfk13 gene: Plasmodium falciparum Kelch-13 gene

BLAST: Basic Local Alignment Search Tool

PDB: Protein Data Bank

PfPP: Plasmodium falciparum protein phosphatase

\section{Declarations}

\section{Ethics approval and consent to participate}

Not applicable.

\section{Consent for publication}

All authors read and agreed to publish the study.

\section{Competing interests}

The authors declare that they have no competing interests.

\section{Funding}

Not applicable.

\section{Authors' contributions}

FA, HW and S.J performed the analysis and prepared the initial draft. MA, IA, SS and SGA reviewed the critical analysis and helped in draft final version preparation. AK finalized the draft and supervised the overall study. All authors have read and agreed to the published version of the manuscript.

\section{Acknowledgements}

Not applicable.

\section{References}

1. Bakhraibah AO. Malaria in Modern Day: A review article. Aust J Basic Appl Sci. 2018;12:73-5. 
2. Rich SM, Leendertz FH, Xu G, LeBreton M, Djoko CF, Aminake MN, et al. The origin of malignant malaria. Proc Natl Acad Sci. 2009;106:14902-7.

3. Perkins DJ, Were T, Davenport GC, Kempaiah P, Hittner JB, Ong'echa JM. Severe malarial anemia: innate immunity and pathogenesis. Int J Biol Sci. 2011;7:1427.

4. Perlmann P, Troye-Blomberg M. Malaria blood-stage infection and its control by the immune system. Folia Biol (Praha). 2000;46:210-8.

5. Baingana FK, Bos ER. Changing patterns of disease and mortality in Sub-Saharan Africa: an overview. Dis Mortal Sub-Saharan Africa 2nd Ed. The International Bank for Reconstruction and Development/The World Bank; 2006;

6. WHO. World malaria report 2020. Geneva, World Health Organization. https ://www.who.int/publi catio ns/i/item/world -malar iarepor t-2019.

7. Bhatia R, Rastogi RM, Ortega L. Malaria successes and challenges in Asia. J Vector Borne Dis. 2013;50:239.

8. Zuber JA, Takala-Harrison S. Multidrug-resistant malaria and the impact of mass drug administration. Infect Drug Resist. 2018;11:299.

9. Lim P, Chy S, Ariey F, Incardona S, Chim P, Sem R, et al. pfcrt polymorphism and chloroquine resistance in Plasmodium falciparum strains isolated in Cambodia. Antimicrob Agents Chemother. 2003;47:87-94.

10. Trape J-F. The public health impact of chloroquine resistance in Africa. Am J Trop Med Hyg. 2001;64:12-7.

11. Hyde JE. Drug-resistant malaria- an insight. FEBS J. 2007;274:4688-98.

12. Dondorp AM, Nosten F, Yi P, Das D, Phyo AP, Tarning J, et al. Artemisinin resistance in Plasmodium falciparum malaria. N Engl J Med. 2009;361:455-67.

13. Noedl H, Se Y, Schaecher K, Smith BL, Socheat D, Fukuda MM. Evidence of artemisinin-resistant malaria in western Cambodia. $N$ Engl J Med. 2008;359:2619-20.

14. Ouji M, Augereau J-M, Paloque L, Benoit-Vical F. Plasmodium falciparum resistance to artemisinin-based combination therapies: A sword of Damocles in the path toward malaria elimination. Parasite. 2018;25.

15. Dong Y, Wang J, Sun A, Deng Y, Chen M, Xu Y, et al. Genetic association between the Pfk13 gene mutation and artemisinin resistance phenotype in Plasmodium falciparum isolates from Yunnan Province, China. Malar J. 2018;17:1-12.

16. Zhang M, Wang C, Otto TD, Oberstaller J, Liao X, Adapa SR, et al. Uncovering the essential genes of the human malaria parasite Plasmodium falciparum by saturation mutagenesis. Science (80-). American Association for the Advancement of Science; 2018;360.

17. Bushell E, Gomes AR, Sanderson T, Anar B, Girling G, Herd C, et al. Functional profiling of a Plasmodium genome reveals an abundance of essential genes. Cell. 2017;170:260-72.

18. Huang Y, Niu B, Gao Y, Fu L, Li W. CD-HIT Suite: a web server for clustering and comparing biological sequences. Bioinformatics. 2010;26:680-2.

19. Johnson M, Zaretskaya I, Raytselis Y, Merezhuk Y, McGinnis S, Madden TL. NCBI BLAST: a better web interface. Nucleic Acids Res. 2008;36:W5-W9.

20. Mukherjee S, Gangopadhyay K, Mukherjee SB. Identification of potential new vaccine candidates in Salmonella typhi using reverse vaccinology and subtractive genomics-based approach. bioRxiv. 2020;521518.

21. Hasan MA, Khan MA, Sharmin T, Mazumder MHH, Chowdhury AS. Identification of putative drug targets in Vancomycin-resistant Staphylococcus aureus (VRSA) using computer aided protein data analysis. Gene. 2016;575:132-43.

22. Aslam M, Shehroz M, Shah M, Khan MA, Afridi SG, Khan A, et al. Potential druggable proteins and chimeric vaccine construct prioritization against Brucella melitensis from species core genome data. Genomics. 2020;112:1734-45.

23. Sayers S, Li L, Ong E, Deng S, Fu G, Lin Y, et al. Victors: a web-based knowledge base of virulence factors in human and animal pathogens. Nucleic Acids Res. 2019;47:D693-D700.

24. Wishart DS, Feunang YD, Guo AC, Lo EJ, Marcu A, Grant JR, et al. DrugBank 5.0: a major update to the DrugBank database for 2018. Nucleic Acids Res. 2018;46:D1074-D1082.

25. Berman HM, Westbrook J, Feng Z, Gilliland G, Bhat TN, Weissig H, et al. The protein data bank. Nucleic Acids Res. 2000;28:235-42.

26. Uddin R, Jamil F. Prioritization of potential drug targets against $P$. aeruginosa by core proteomic analysis using computational subtractive genomics and Protein-Protein interaction network. Comput Biol Chem. 2018;74:115-22. 
27. Waterhouse A, Bertoni M, Bienert S, Studer G, Tauriello G, Gumienny R, et al. SWISS-MODEL: homology modelling of protein structures and complexes. Nucleic Acids Res. 2018;46:W296-W303.

28. Dym O, Eisenberg D, Yeates TO. ERRAT. Wiley Online Library; 2012;

29. Kleywegt GJ, Jones TA. Phi/psi-chology: Ramachandran revisited. Structure. 1996;4:1395-400.

30. Hussein HA, Borrel A, Geneix C, Petitjean M, Regad L, Camproux A-C. PockDrug-Server: a new web server for predicting pocket druggability on holo and apo proteins. Nucleic Acids Res. 2015;43:W436-W442.

31. Yu C-S, Chen Y-C, Lu C-H, Hwang J-K. Prediction of protein subcellular localization. Proteins Struct Funct Bioinforma. 2006;64:64351.

32. Artimo P, Jonnalagedda M, Arnold K, Baratin D, Csardi G, De Castro E, et al. ExPASy: SIB bioinformatics resource portal. Nucleic Acids Res. 2012;40:W597-W603.

33. Mering C von, Huynen M, Jaeggi D, Schmidt S, Bork P, Snel B. STRING: a database of predicted functional associations between proteins. Nucleic Acids Res. 2003;31:258-61.

34. Oberstaller J, Otto TD, Rayner JC, Adams JH. Essential Genes of the Parasitic Apicomplexa. Trends Parasitol. 2021;

35. Rowland I, Gibson G, Heinken A, Scott K, Swann J, Thiele I, et al. Gut microbiota functions: metabolism of nutrients and other food components. Eur J Nutr. 2018;57:1-24.

36. Yamashiro Y. Gut microbiota in health and disease. Ann Nutr Metab. 2017;71:242-6.

37. Solanki V, Tiwari V. Subtractive proteomics to identify novel drug targets and reverse vaccinology for the development of chimeric vaccine against Acinetobacter baumannii. Sci Rep. 2018;8:1-19.

38. Hadizadeh M, Tabatabaiepour SN, Tabatabaiepour SZ, Hosseini Nave H, Mohammadi M, Sohrabi SM. Genome-wide identification of potential drug target in enterobacteriaceae family: a homology-based method. Microb Drug Resist. Mary Ann Liebert, Inc. 140 Huguenot Street, 3rd Floor New Rochelle, NY 10801 USA; 2018;24:8-17.

39. Messaoudi A, Belguith $\mathrm{H}$, Hamida J Ben. Homology modeling and virtual screening approaches to identify potent inhibitors of VEB-1 \$\$-lactamase. Theor Biol Med Model. 2013;10:1-10.

40. Gaudet P, Livstone MS, Lewis SE, Thomas PD. Phylogenetic-based propagation of functional annotations within the Gene Ontology consortium. Brief Bioinform. 2011;12:449-62.

41. Guranowski A, Jakubowski H, Holler E. Catabolism of diadenosine 5', 5 “'-P1, P4-tetraphosphate in procaryotes. Purification and properties of diadenosine 5', 5''-P1, P4-tetraphosphate (symmetrical) pyrophosphohydrolase from Escherichia coli K12. J Biol Chem. 1983;258:14784-9.

42. Osman W, Endo S, Oh-Hashi K, Kitamura Y, Kitade Y. Molecular Characterization and Mutational Analysis of Recombinant Diadenosine 5', 5 "-P1, P4-Tetraphosphate Hydrolase from Plasmodium falciparum. Biol Pharm Bull. The Pharmaceutical Society of Japan; 2012;35:1191-6.

43. Guranowski A, Starzyńska E, Pietrowska-Borek M, Rejman D, Blackburn GM. Novel diadenosine polyphosphate analogs with oxymethylene bridges replacing oxygen in the polyphosphate chain: potential substrates and/or inhibitors of Ap4A hydrolases. FEBS J. 2009;276:1546-53.

44. Guranowski A, Starzyska E, Mclennan AG, Baraniak J, Stec WJ. Adenosine-5'-0-phosphorylated and adenosine-5'-0phosphorothioylated polyols as strong inhibitors of (symmetrical) and (asymmetrical) dinucleoside tetraphosphatases. Biochem $\mathrm{J}$. 2003;373:635-40.

45. Shi Y. Serine/threonine phosphatases: mechanism through structure. Cell. 2009;139:468-84.

46. Yang C, Arrizabalaga G. The serine/threonine phosphatases of apicomplexan parasites. Mol Microbiol. 2017;106:1-21.

47. Yokoyama D, Saito-lto A, Asao N, Tanabe K, Yamamoto M, Matsumura T. Modulation of the Growth ofPlasmodium falciparum in Vitroby Protein Serine/Threonine Phosphatase Inhibitors. Biochem Biophys Res Commun. 1998;247:18-23.

48. Khalife J, Pierrot C. Phosphatases are emerging as novel druggable targets in Plasmodium. Future Medicine; 2016.

49. Dounay AB, Forsyth CJ. Okadaic acid: the archetypal serine/threonine protein phosphatase inhibitor. Curr Med Chem. 2002;9:193980.

50. Zhang M, Mishra S, Sakthivel R, Fontoura BMA, Nussenzweig V. UIS2: a unique phosphatase required for the development of Plasmodium liver stages. PLoS Pathog. 2016;12:e1005370.

51. Malvisi L. Functional characterization of cytochrome b5 reductase and its electron acceptor cytochrome b5 in Plasmodium falciparum. 2009;

Page 9/12 
52. Maier AG, Cooke BM, Cowman AF, Tilley L. Malaria parasite proteins that remodel the host erythrocyte. Nat Rev Microbiol. 2009;7:341-54.

53. Iqbal MS, Siddiqui AA, Banerjee C, Nag S, Mazumder S, De R, et al. Detection of retromer assembly in Plasmodium falciparum by immunosensing coupled to Surface Plasmon Resonance. Biochim Biophys Acta (BBA)-Proteins Proteomics. 2018;1866:722-30.

54. Iqbal MS, Siddiqui AA, Alam A, Goyal M, Banerjee C, Sarkar S, et al. Expression, purification and characterization of Plasmodium falciparum vacuolar protein sorting 29. Protein Expr Purif. 2016;120:7-15.

55. Copeland RA, Solomon ME, Richon VM. Protein methyltransferases as a target class for drug discovery. Nat Rev Drug Discov. 2009;8:724-32.

56. Brecher M, Chen H, Liu B, Banavali NK, Jones SA, Zhang J, et al. Novel broad spectrum inhibitors targeting the flavivirus methyltransferase. PLoS One. 2015;10:e0130062.

57. Ahmad M, Tuteja R. Plasmodium falciparum RuvB proteins: emerging importance and expectations beyond cell cycle progression. Commun Integr Biol. 2012;5:350-61.

58. Ahmad M, Tuteja R. Plasmodium falciparum RuvB1 is an active DNA helicase and translocates in the 5'-3' direction. Gene. 2013;515:99-109.

59. Jha S, Dutta A. RVB1/RVB2: running rings around molecular biology. Mol Cell. 2009;34:521-33.

60. Qiu X-B, Lin Y-L, Thome KC, Pian P, Schlegel BP, Weremowicz S, et al. An eukaryotic RuvB-like protein (RUVBL1) essential for growth. J Biol Chem. 1998;273:27786-93.

61. Bauer A, Chauvet S, Huber O, Usseglio F, Rothbächer U, Aragnol D, et al. Pontin52 and Reptin52 function as antagonistic regulators of $\$ \beta \$$-catenin signalling activity. EMBO J. 2000;19:6121-30.

62. Matias PM, Gorynia S, Donner P, Carrondo MA. Crystal structure of the human AAA+ protein RuvBL1. J Biol Chem. 2006;281:3891829.

63. Ahmad M, Tuteja R. Plasmodium falciparum RuvB2 translocates in 5'-3' direction, relocalizes during schizont stage and its enzymatic activities are up regulated by RuvB3 of the same complex. Biochim Biophys Acta (BBA)-Proteins Proteomics. 2013;1834:2795-811.

64. Ahmad M, Singh S, Afrin F, Tuteja R. Novel RuvB nuclear ATPase is specific to intraerythrocytic mitosis during schizogony of Plasmodium falciparum. Mol Biochem Parasitol. 2012;185:58-65.

65. Borowski P, Lang M, Haag A, Schmitz H, Choe J, Chen H-M, et al. Characterization of imidazo [4, 5-d] pyridazine nucleosides as modulators of unwinding reaction mediated by West Nile virus nucleoside triphosphatase/helicase: evidence for activity on the level of substrate and/or enzyme. Antimicrob Agents Chemother. 2002;46:1231-9.

66. Frick DN. Helicases as antiviral drug targets. Drug News Perspect. NIH Public Access; 2003;16:355.

67. Tuteja R. Helicases- feasible antimalarial drug target for Plasmodium falciparum. FEBS J. 2007;274:4699-704.

68. Ahmad M, Tarique M, Afrin F, Tuteja N, Tuteja R. Identification of inhibitors of Plasmodium falciparum RuvB1 helicase using biochemical assays. Protoplasma. 2015;252:117-25.

\section{Figures}


(C)

Retrieval of Essential Protein

(from published articles)
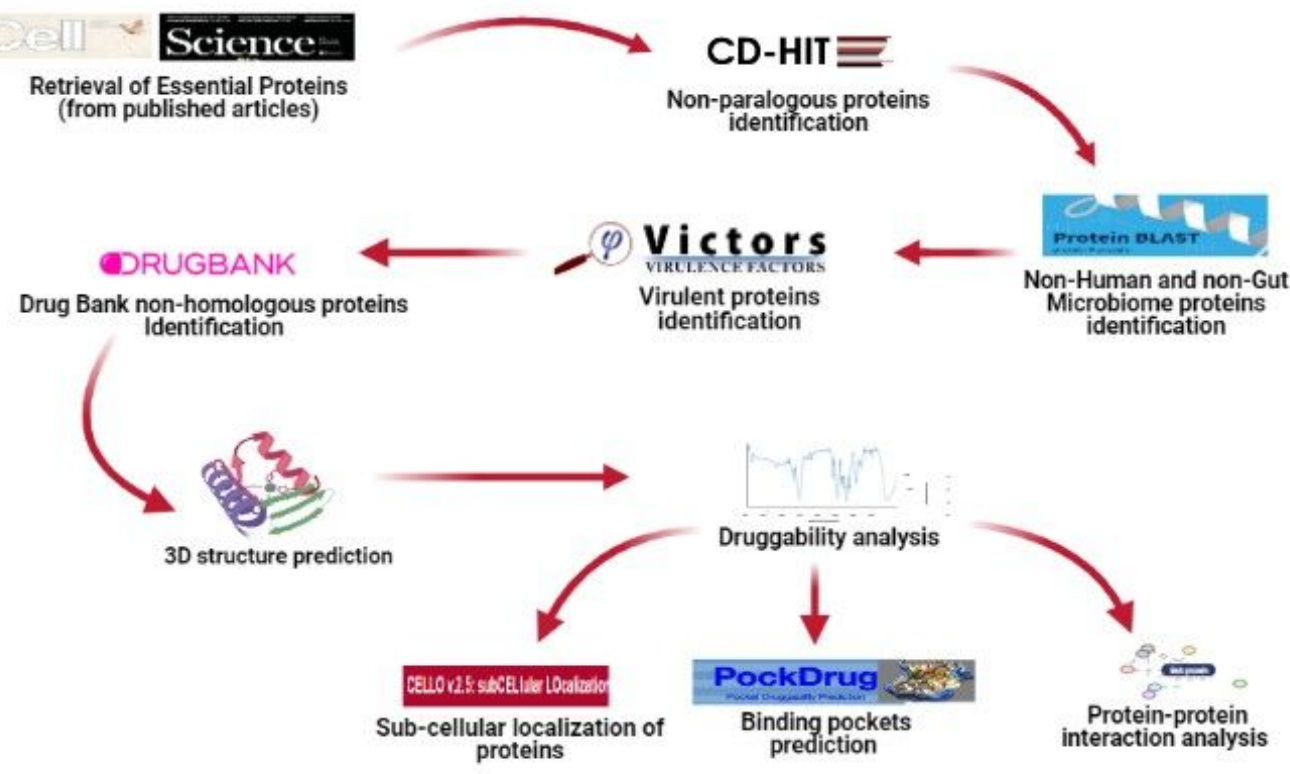

Created in BioRender.com bio

Figure 1

The stepwise workflow adopted for novel anti-malarial drug targets identification.
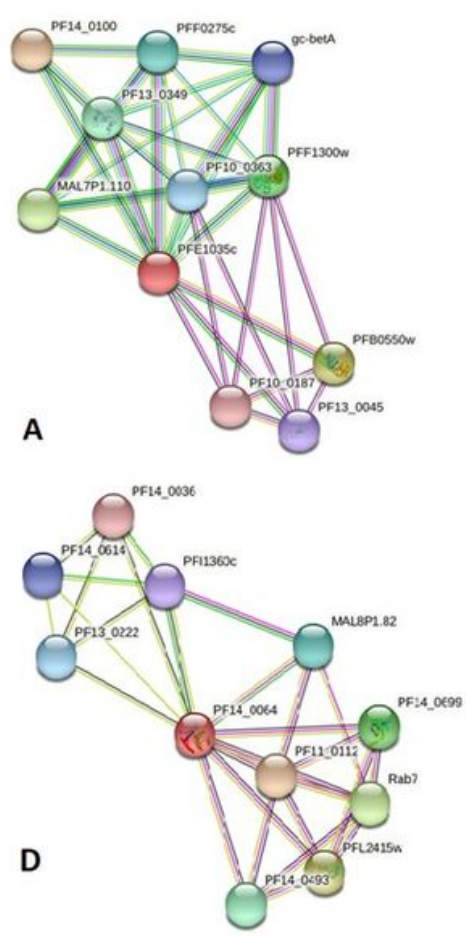

B
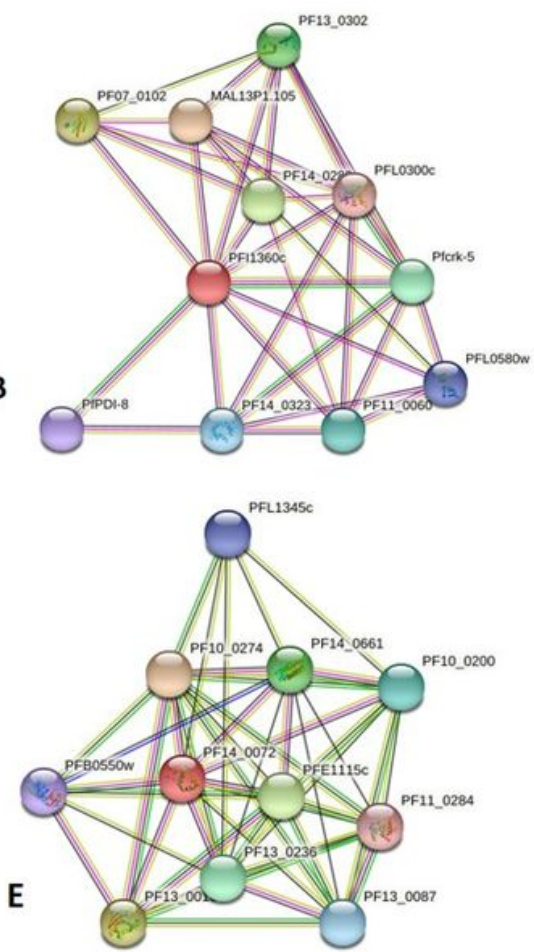

C
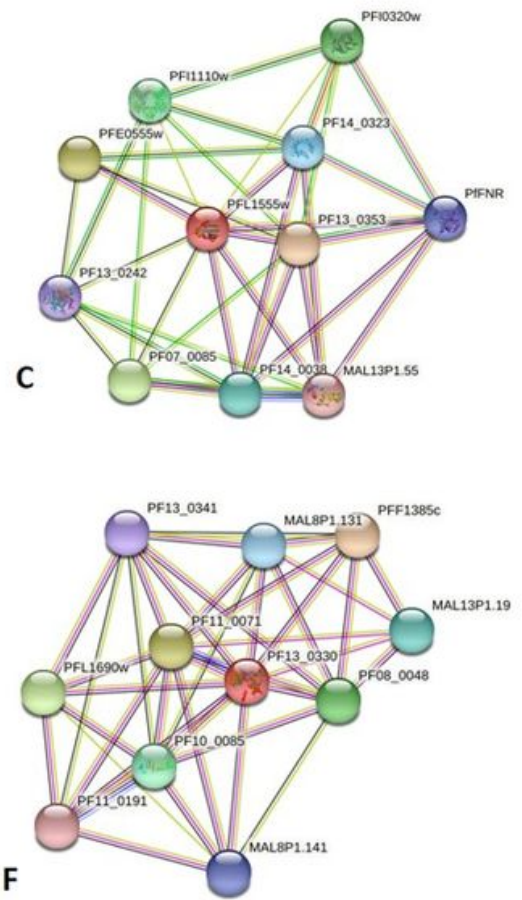

\section{Figure 2}

Protein-protein interaction plots of best interacting proteins. The red color indicates query protein. (A) Bis(5'-nucleosyl)-tetraphosphatase.

(B) Serine/threonine-protein phosphatase. (C) Cytochrome b5, putative. (D) Vacuolar protein sorting-associated protein 29. (E) 
Multifunctional methyltransferase subunit TRM112, putative. (F) RuvB-like helicase. All these proteins showed vital interaction with other P.falciparum proteins.

\section{Supplementary Files}

This is a list of supplementary files associated with this preprint. Click to download.

- SupplimentaryTableS1.xlsx

- SupplimentaryTableS2.xIsx 